\title{
CERVICAL SPINE INJURIES IN THE ELDERLY
}

ISADOR H. LIEBERMAN, JOHN K. WEBB

\author{
From University Hospital, Queen's Medical Centre, Nottingham, England
}

We reviewed 41 patients over the age of 65 years (mean 76.5) who had suffered cervical spine injuries, 12 of them with neurological deficit. Eleven patients died during treatment, mostly from respiratory disease. Seven patients were treated by surgical stabilisation, five by halo traction, and the rest by rigid collars or halo-vests. The cervical injury was missed at the first examination in four patients.

We conclude that most injuries can be treated by a rigid collar, and that the use of a halo-vest or surgical stabilisation are effective alternatives. Bed rest and traction are poorly tolerated by old people. There should be a high index of suspicion that any elderly patient who presents with a history of a fall or minor trauma may have a cervical spine injury.

J Bone Joint Surg [Br] 1994; 76-B:877-81.

Received 12 January 1994; Accepted 24 February 1994

Very little information has been published regarding the treatment and outcome of cervical spine injuries in the elderly. There are a few articles which deal specifically with odontoid fractures (Pepin, Bourne and Hawkins 1985; Hanigan et al 1993), but to obtain information about subaxial injuries one must extrapolate from articles on patients from a wide age spectrum, and which include only a few elderly patients.

Our aim was to determine the mortality and morbidity of cervical spine injuries in the elderly and to ascertain the best methods for their treatment.

\section{PATIENTS AND METHODS}

We found that 234 patients with cervical spine injuries had been admitted to the Queen's Medical Centre, Nottingham between January 1982 and January 1993; 46 of these were more than 65 years old. We retrieved their hospital charts, post-mortem reports and radiographs and

I. H. Lieberman, FRCS C, Clinical Spinal Fellow

J. K. Webb, FRCS, Consultant Spinal Surgeon

Centre for Spinal Studies and Surgery, University Hospital, Queen's Medical Centre, Clifton Boulevard, Nottingham NG7 2UH, UK.

Correspondence should be sent to Mr J. K. Webb.

(C)1994 British Editorial Society of Bone and Joint Surgery 0301-620X/94/6831\$2.00 when these notes were incomplete we contacted the general practitioners and nursing homes for further information. We were able to obtain complete data on 41 patients, which we attempted to review. Most, however, had either died from causes related or unrelated to their cervical spine injury or were too ill to return to hospital for review. In these cases we relied upon the orthopaedic surgeon's last clinical assessment and the general practitioner's evaluation to determine the clinical outcome.

We recorded the patient's age at the time of injury, the mechanism, pattern and level of injury, any neurological deficit and associated systemic injuries. We noted the previous medical and surgical history, the initial and subsequent treatment of the cervical injury, and the complications and duration of treatment. Outcome was recorded in terms of return to preinjury status, the resolution of neurological deficit and the healing of the bone and soft-tissue injuries.

We reviewed the post-mortem reports of the patients who had died during treatment to determine the extent to which the cervical spine injury had contributed to death. We examined the radiographs to verify the diagnosis and pattern of injury recorded in the notes and to assess the final outcome.

There were 23 men and 18 women and their ages ranged from 65 to 91 years (mean 76.5).

\section{RESULTS}

A fall in the home was the cause of injury in 32 of the 41 patients. Eight were pedestrians involved in a vehicle accident and one was injured while a passenger in a motor vehicle (Table I). Two patients had two fractures.

There were 16 odontoid injuries, 11 type 2 and five type 3 as classified by Anderson and D'Alonzo (1974). There were three Jefferson's fractures (Jefferson 1927), one isolated, one in combination with a $\mathrm{C} 2-\mathrm{C} 3$ bilateral facet-dislocation, and one in combination with an odontoid type-3 fracture. There were three 'hangman's' fractures. In the subaxial spine there were four compression-type injuries, three extension injuries, 12 bilateral facetdislocations, and two unilateral facet-dislocations (Table I). Two patients had two fractures.

Twenty-six patients had no neurological deficit. Of the 12 patients with nerve injury, eight had no recovery. These included three complete quadriplegics two of whom died, one progressive quadriparetic who also died, two other quadriparetics, one patient with a Brown-Sequard 
Table I. Details of 41 patients with cervical spine injuries

\begin{tabular}{|c|c|c|c|c|c|c|c|c|c|}
\hline Case & $\begin{array}{l}\text { Age } \\
(\mathbf{y r})\end{array}$ & $\begin{array}{l}\text { Date of } \\
\text { admission }\end{array}$ & Sex & $\begin{array}{l}\text { Mechanism } \\
\text { of injury }\end{array}$ & Injury & Neurology & Treatment & \multicolumn{2}{|c|}{ Outcome/neurology } \\
\hline 1 & 80 & $1 / 82$ & $\mathbf{F}$ & Fall & C4 compression & - & Collar & Stable & \\
\hline 2 & 86 & $4 / 83$ & $\mathbf{F}$ & Fall & Odontoid 2 & - & Collar & Died & \\
\hline 3 & 73 & $12 / 83$ & $\mathbf{F}$ & RTA* & Odontoid 2 & - & Collar & Stable & \\
\hline 4 & 74 & $2 / 84$ & $\mathbf{F}$ & Fall & C6-C7 bilat facet-disloc & Complete quadriparesis & Collar & Died & \\
\hline 5 & 74 & $2 / 84$ & $\mathbf{F}$ & PVAt & Odontoid 3 & - & Collar & Stable & \\
\hline 6 & 79 & $3 / 84$ & $\mathbf{M}$ & PVA & C6-C7 bilat facet-disloc & - & Collar & Died & \\
\hline 7 & 72 & $1 / 85$ & $\mathbf{F}$ & Fall & C6-C7 bilat facet-disloc & - & Collar & Stable & \\
\hline 8 & 74 & $3 / 85$ & $\mathbf{M}$ & Fall & C4-C5 compression & Not known & Collar & Died & \\
\hline 9 & 67 & $6 / 85$ & $\mathbf{M}$ & Fall & Odontoid 2 & Quadriparesis & Surgery & Stable & Resolved \\
\hline 10 & 75 & $8 / 85$ & $\mathbf{F}$ & Fall & Odontoid 2 & - & Collar & Stable & \\
\hline 11 & 82 & $11 / 85$ & $\mathbf{F}$ & PVA & Odontoid $2 \ddagger$ & - & Surgery & Stableq & \\
\hline 12 & 68 & $12 / 85$ & $\mathbf{M}$ & Fall & C6-C7 bilat facet-disloc $\ddagger$ & Quadriparesis & Surgery & Stable & Resolved \\
\hline 13 & 69 & $2 / 86$ & $\mathbf{F}$ & Fall & C5-C6 extension & - & Collar & Stable & \\
\hline 14 & 86 & $5 / 86$ & $\mathbf{F}$ & Fall & C7-T1 bilat facet-disloc $\ddagger$ & - & Collar & Stable & \\
\hline 15 & 69 & $3 / 87$ & $\mathbf{M}$ & Fall & Odontoid 2 & - & Surgery & Died & \\
\hline 16 & 66 & $6 / 87$ & $\mathbf{M}$ & Fall & Jefferson's & - & Collar & Stable & \\
\hline 17 & 68 & $7 / 87$ & $\mathbf{M}$ & Fall & C6-C7 bilat facet-disloc & Quadriparesis & Traction & Stable & Persistent \\
\hline 18 & 65 & $8 / 87$ & $\mathbf{M}$ & Fall & Hangman's & - & Traction & Died & \\
\hline 19 & 81 & $9 / 87$ & $\mathbf{M}$ & Fall & Hangman's & - & Collar & Stable & \\
\hline 20 & 68 & $3 / 88$ & $\mathbf{M}$ & PVA & C4-C5 extension & Not known & Collar & Died & \\
\hline 21 & 70 & $6 / 88$ & $\mathbf{M}$ & Fall & C6-C7 unilat facet-disloc & Quadriparesis & Collar & Stable & Persistent \\
\hline 22 & 91 & $7 / 88$ & $\mathbf{F}$ & Fall & Odontoid 2 & - & Collar & Stable & \\
\hline 23 & 78 & $7 / 88$ & $\mathbf{F}$ & Fall & Odontoid 2 & - & Halo-vest & Stable & \\
\hline 24 & 79 & $12 / 88$ & $\mathbf{M}$ & PVA & $\mathrm{C} 6-\mathrm{C} 7$ unilat facet-disloc & - & Traction & Stable & \\
\hline 25 & 86 & $1 / 89$ & $\mathbf{M}$ & Fall & Odontoid 2 & - & Collar & Died & \\
\hline 26 & 78 & $1 / 89$ & $\mathbf{F}$ & Fall & Hangman's & - & Collar & Stable & \\
\hline 27 & 65 & $3 / 89$ & $\mathbf{F}$ & Fall & C4-C5 bilat facet-disloc & Complete quadriparesis & Surgery & Stable & Persistent \\
\hline 28 & 78 & $7 / 89$ & $\mathbf{M}$ & Fall & C4-C5 bilat facet-disloc & - & Halo-vest & Stable & \\
\hline 29 & 74 & 9/89 & $\mathbf{M}$ & Fall & Odontoid 3 & Quadriparesis & Collar & Stable & Resolved \\
\hline 30 & 76 & $3 / 90$ & $\mathbf{M}$ & PVA & C4-C5-C6 bilat facet-disloc & Complete quadriparesis & Collar & Died & \\
\hline 31 & 68 & $9 / 90$ & $\mathbf{M}$ & Fall & C6 compression $\ddagger$ & - & Collar & Stable & \\
\hline 32 & 75 & $12 / 90$ & $\mathbf{F}$ & Fall & Jefferson/odontoid 3 & Radiculopathy & Collar & Stable & Persistent \\
\hline 33 & 75 & $11 / 91$ & $\mathbf{M}$ & Fall & C7 compression§ & Brown-Sequard & Surgery & Stable & Persistent \\
\hline 34 & 82 & $11 / 91$ & $\mathbf{M}$ & Fall & Odontoid 3 & - & Collar & Stable & \\
\hline 35 & 85 & $1 / 92$ & $\mathbf{F}$ & Fall & Odontoid 2 & - & Halo-vest & Stable & \\
\hline 36 & 91 & 2/92 & $\mathbf{F}$ & Fall & Odontoid 3 & - & Halo-vest & Stable & \\
\hline 37 & 84 & $4 / 92$ & $\mathbf{M}$ & Fall & C5-C6 extension & Quadriparesis & Trac/sur & Stable & Resolved \\
\hline 38 & 75 & $8 / 92$ & $\mathbf{M}$ & PVA & C6-C7 bilat facet-disloc & Not known & Collar & Died & \\
\hline 39 & 79 & $8 / 92$ & $\mathbf{F}$ & Fall & Jefferson/C2-C 3 bilat facet-disloc & - & Collar & Stable & \\
\hline 40 & 81 & $1 / 93$ & $\mathbf{M}$ & PVA & C5-C6 bilat facet-disloc $\ddagger$ & Quadriparesis & Traction & Died & Progressive \\
\hline 41 & 88 & $1 / 93$ & $\mathbf{M}$ & Fall & Odontoid 2 & - & Halo-vest & Stable & \\
\hline
\end{tabular}


lesion, and one with radiculopathy. Of the last five of these patients (cases 17, 21, 27, 32 and 33), two had been treated surgically, two by a rigid collar and one by traction; they all finally had stable spines. Four patients were quadriparetic on presentation and completely recovered. Three patients had severe head injuries and it was impossible to assess their spinal-cord function (Table I).

Twenty-five patients were treated initially by a rigid collar, five by a halo-vest, and five by halo traction. One of these subsequently had an operation having been unable to tolerate the halo-traction. The remaining six patients were treated by immediate operation.

Twenty-four patients made a full recovery from the injury, returned to their preinjury status, and had full stability of the cervical spine. Twenty of these had been treated by a halo-vest or a rigid collar, two had been treated by primary surgery, one by halo-traction and one by halo-traction followed by surgery. Among the patients treated by a halo-vest there were two cases of pin-site infections; in those treated by a rigid collar there were no recorded complications. No patient treated by a rigid collar or a halo-vest lost reduction of the spine or developed neurological symptoms.

Of the five patients who had been treated primarily by halo-traction, two (cases 17 and 24) tolerated it for six and eight weeks respectively, two (cases 18 and 40) died at two and three days respectively, and the fifth (case 37 ) had respiratory problems and subsequently underwent surgery.

Eleven patients died during treatment at a mean of 5.4 days after admission (Table II). Five had been injured in falls and six in pedestrian vehicle accidents. Seven of the ten had other injuries which contributed to their deaths. Head injury (seen in nine patients) and respiratory failure were the typical final common pathway. One patient (case 15) had unrecognised metastatic disease of the spine and died 18 weeks after admission from systemic metastases.

Twenty-four patients had associated injuries which included fracture of the long bones (12), head injuries (10), chest injuries (2) and splenic rupture (1). Four patients had lacerations and contusions.

In four patients the cervical injury was missed (Table I). One of these (case 11) had an odontoid type-2 fracture, diagnosed because of persistent pain four weeks after the injury. She was at first treated by anterior screw fixation of the odontoid but this failed and a posterior $\mathrm{C} 1-\mathrm{C} 2$ fusion was performed. Another (case 12) had C6-C7 bilateral facet-dislocations and presented with progressive quadriparesis four weeks after injury. He was treated by halo-traction reduction followed by anterior fusion and had an uneventful recovery. A third patient (case 31) who had a C6 compression fracture, returned to the emergency department two days after his first visit complaining of persistent pain. He was treated by a collar and made a full recovery. The fourth (case 40) who had C5-C6 bilateral facet-dislocations was admitted to hospital for traction treatment of an acetabular fracture; 48 hours after admission he was quadriparetic. Radiographs then revealed C5-C6 bilateral facet-dislocations which had not been evident on the admission films. He died on the third day as a result of respiratory failure.

Of the seven surgically treated patients (Table III), three underwent operation for neurological indications, three for instability, and one because he could not tolerate halo-traction. The patients with neurological deficit were not improved by surgery. Two of the other four patients achieved solid fusions, but the two with odontoid fractures

Table II. Details of patient deaths

\begin{tabular}{|c|c|c|c|c|c|}
\hline Case & $\begin{array}{l}\text { Age } \\
\text { (yr) }\end{array}$ & Injury & $\begin{array}{l}\text { Associated } \\
\text { injuries }\end{array}$ & $\begin{array}{l}\text { Time from injury } \\
\text { to death (days) }\end{array}$ & Cause of death \\
\hline 2 & 86 & Odontoid 2 & - & 15 & Medical condition \\
\hline 4 & 74 & C6-C7 bilateral facet-dislocation & - & 2 & Respiratory failure \\
\hline 6 & 79 & C6- 7 bilateral facet-dislocation & $\begin{array}{l}\text { Head, chest, } \\
\text { spleen, ankle }\end{array}$ & 9 & $\begin{array}{l}\text { Multiple injuries and } \\
\text { respiratory failure }\end{array}$ \\
\hline 8 & 74 & C4-C5 compression & Head & 1 & Head injury \\
\hline 15 & 69 & Odontoid 2 & - & 135 & Metastatic lung disease \\
\hline 18 & 65 & Hangman's & - & 2 & Respiratory failure \\
\hline 20 & 68 & C4-C5 extension & Head, extremity & 14 & $\begin{array}{l}\text { Head injury and } \\
\text { respiratory failure }\end{array}$ \\
\hline 25 & 86 & Odontoid 2 & Head & 6 & $\begin{array}{l}\text { Head injury and } \\
\text { respiratory failure }\end{array}$ \\
\hline 30 & 76 & $\begin{array}{l}\mathrm{C} 4-\mathrm{C} 5-\mathrm{C} 6 \text { bilateral facet- } \\
\text { dislocation }\end{array}$ & Head, chest & 1 & $\begin{array}{l}\text { Spinal injury and } \\
\text { respiratory failure }\end{array}$ \\
\hline 38 & 75 & C6-C7 bilateral facet-dislocation & Head & 1 & Head injury \\
\hline 40 & 81 & C5-C6 bilateral facet-dislocation & Extremity & 3 & $\begin{array}{l}\text { Spinal and extremity injury } \\
\text { and respiratory failure }\end{array}$ \\
\hline
\end{tabular}


Table III. Details of surgically treated patients

\begin{tabular}{clllll}
\hline Case & Injury & Indication & Procedure & Fusion & Neurology \\
\hline 9 & Odontoid 2 & Instability/neurology & Posterior C1-C2 fusion & Solid & Resolved \\
11 & Odontoid 2 & $\begin{array}{l}\text { Instability, } \\
\text { surgical failure }\end{array}$ & $\begin{array}{l}\text { Anterior dens screw } \\
\text { Posterior } \mathrm{C} 1-\mathrm{C} 2 \text { fusion }\end{array}$ & $\begin{array}{l}\text { Cut out } \\
\text { Solid }\end{array}$ & \\
12 & $\begin{array}{l}\text { C6-C7 bilateral } \\
\text { facet-dislocation }\end{array}$ & Neurology/instability & Posterior fusion & Solid & Resolved \\
15 & Odontoid 2 & Instability & Anterior dens screw & Cut out & \\
27 & $\begin{array}{l}\text { C4-C5 bilateral } \\
\text { facet-dislocation }\end{array}$ & Neurology/instability & Posterior fusion & Solid & No recovery \\
33 & C7 compression & Neurology & Laminectomy and fusion & Solid & No recovery \\
37 & C5-C6 extension & Traction failure & Anterior fusion & Solid & \\
\hline
\end{tabular}

which had been treated initially by anterior screw fixation were failures (cases 11 and 15).

\section{DISCUSSION}

The earliest reference to the high mortality of cervical spine injuries in the elderly is in Samuel 1, 4:18 and describes the death of Eli, the 94-year-old high priest of Israel, as follows:

"and it came to pass, when he made mention of the ark of God (to the Philistines), that he (Eli) fell from off the seat backward by the side of the gate, and his neck brake, and he died; for he was an old man and heavy."

Anderson and D'Alonzo (1974) in their series of 49 patients with odontoid fractures whose ages ranged from 3 to 86 years reported two deaths one of which was an 86-year-old patient who had been treated in traction.

Pepin et al (1985) described 19 elderly patients with odontoid fractures and reported that three had died during treatment by halo-vests. They cited two patients treated surgically who had good outcomes and concluded that halo-vest treatment is poorly tolerated by the elderly and that early fusion or a rigid collar are the treatments of choice.

Bucholz and Cheung (1989) reported on the outcome of halo-vest treatment as against spinal fusion for cervical injuries. Their series of 124 patients included 30 who were over the age of 65 years and they concluded that age did not influence outcome after halo-vest treatment.

Rockswold, Bergman and Ford (1990) described 41 patients who had been treated surgically. Of the three who died, one was a 73-year-old who had a cerebrovascular accident and the other was a 76-year-old who developed renal failure.

Anderson and Bohlman (1992) and Bohlman and Anderson (1992) in their articles on anterior decompression and arthrodesis included five patients over the age of 65 years. They reported that of the three with incomplete cord injuries who had had anterior decompression and fusion two had a poor outcome and one did well. The other two elderly patients presented with complete cord injuries and died after surgery. They concluded that surgery is contraindicated in old people with complete cord injury.

Hanigan et al (1993) described 19 elderly patients with odontoid fractures. Five treated surgically with posterior cervical fusions had good results but of the 14 treated non-operatively five died, and five recovered, three had stable nonunion and one had an unstable nonunion. They concluded that in the elderly, fibrous union of the odontoid is an adequate goal, and that a rigid collar provides sufficient immobilisation.

In our series there were 11 deaths over a ten-year period, seven from respiratory failure directly attributable to the spinal injury. These deaths prove the vulnerability and limited physiological reserve of injured elderly patients.

Twelve of our patients had spinal cord injuries, of whom only four recovered neurologically. In the elderly minor trauma can cause serious cord damage, and our experience confirms the opinion of Anderson and Bohlman (1992) that the potential for recovery is limited.

In four of our patients the spinal injury was missed at the first examination. One died and one had a compromised recovery. Any elderly patient who presents with a history even of minor trauma or a fall and is suspected of having a head or neck injury must be examined and re-examined to rule out cervical spine damage.

Of the 30 patients in this study who were treated by a rigid collar or a halo-vest, 22 recovered uneventfully. Only two pin-site infections occurred and no patient had late instability or neurological progression. The other eight patients initially treated in this way all died, for reasons which were unrelated to the method of treatment (see Table II). It appears that in the elderly a rigid collar or a halo-vest provides adequate stability until healing has occurred.

Six of our seven patients treated surgically achieved sound fusion, one after reoperation because the screw cut out. It is our experience that surgery is well tolerated in the elderly and that bony fusion is achievable. These 
results support the conclusions of Pepin et al (1985) and Hanigan et al (1993).

The aims of treatment of cervical spine injuries are very different in the elderly and the young. In old people the first goal is to keep the patient mobile in order to promote maximum respiratory function and maintain mental health. This can be achieved in most cases by a rigid collar. If the spine is very unstable or there are multiple injuries then the use of a halo-vest or surgical stabilisation are effective alternatives. Traction and bedrest are inappropriate for the elderly.

Our study suffers from the limitations of any retrospective review. We were unable to determine with certainty how many of the injured spines did in fact achieve solid stable healing although we do know that no patient had progressive instability or late neurological deterioration. Bony union is not always necessary in the elderly; in odontoid fractures particularly, a stable fibrous union may be an acceptable result.

No benefits in any form have been received or will be received from a commercial party related directly or indirectly to the subject of this article.

\section{REFERENCES}

Anderson LD, D'Alonzo RT. Fractures of the odontoid process of the axis. J Bone Joint Surg [Am] 1974; 56-A:1663-74.

Anderson PA, Bohlman HH. Anterior decompression and arthrodesis of the cervical spine: long-term motor improvement Part II: improvement in complete traumatic quadriplegia. J Bone Joint Surg [Am] 1992; 74A:683-92.

Bohlman HH, Anderson PA. Anterior decompression and arthrodesis of the cervical spine: long term improvement. Part I: improvement in incomplete traumatic quadriparesis. J Bone Joint Surg [Am] 1992:74A:671-82.

Bucholz RD, Cheung KC. Halo vest versus spinal fusion for cervical injury: evidence from an outcome study. J Neurosurg 1989; 70 : 894-92.

Hanigan WC, Powell FC, Elwood PW, Henderson JP. Odontoid fractures in elderly patients. $J$ Neurosurg $1993 ; 78: 32-5$.

Jefiferson G. Remarks on fractures of the first cervical vertebra. Br Med J 1927; July 30:153-7.

Pepin JW, Bourne RB, Hawkins RJ. Odontoid fracture, with special reference to the elderly patient. Clin Orthop 1985; 193:178-83.

Rockswold GL, Bergman TA, Ford SE. Halo immobilization and surgical fusion: relative indications and effectiveness in the treatment of 140 cervical spine injuries. J Trauma 1990; 30:893-8. 